\title{
Hiperplasia suprarrenal congénita por mutación del gen StAR: revisión de un caso
}

\section{Congenital adrenal hyperplasia associated with mutation in StAR gene: Case report}

\author{
Nayelly Díaz-Flores*, Sletza L. Arguinzoniz-Valenzuela, Raúl Calzada-León, Ma. De la Luz Ruíz-Reyes, \\ Nelly F. Altamirano-Bustamante y Ariadna GonZÁlez-del Ángel
}

Servicio de Endocrinología Pediátrica, Instituto Nacional de Pediatría, Ciudad de México, México

\section{RESUMEN}

La mutación del gen StAR es la causa de la hiperplasia lipoidea adrenal, una forma grave y muy poco frecuente de hiperplasia suprarrenal congénita. Presentamos el caso de una paciente de sexo femenino que fue derivada a nuestro centro a los 23 días de vida con dismorfias faciales y alteraciones electrolíticas. Diagnosticada inicialmente con insuficiencia suprarrenal, el estudio genético posterior puso de manifiesto una mutación en el gen StAR como causante del bloqueo alto de la vía adrenal.

Palabras clave: Hiperplasia lipoidea adrenal. Mutación StAR. Dismorfias. Alteraciones electrolíticas.

\begin{abstract}
The StAR gene mutation is the cause of adrenal lipoid hyperplasia, a very rare and severe form of congenital adrenal hyperplasia. We present the case of a female patient who was referred to our center at 23 days of life with facial dysmorphism and electrolyte alterations. With an early diagnosis of adrenal insufficiency, the subsequent genetic study revealed a mutation in the StAR gene, as the cause of the high adrenal pathway blockage.
\end{abstract}

Keywords: Lipoid congenital adrenal hyperplasia. StAR mutation. Water-electrolyte imbalance.
Correspondencia:

*Nayelly Díaz-Flores

E-mail: nayellydiazf@gmail.com
Fecha de recepción: 20-11-21

Fecha de aceptación: 01-01-22

DOI: 10.24875/RME.M22000022
Disponible en internet: 07-03-2022

Rev Mex Endocrinol Metab Nutr. 2021;8(SUPL. 2):24-28

2462-4144 / @ 2022 Sociedad Mexicana de Nutrición y Endocrinología, AC. Publicado por Permanyer. Este es un artículo open access bajo la licencia CC BY-NC-ND (http://creativecommons.org/licenses/by-nc-nd/4.0/). 


\section{INTRODUCCIÓN}

La hiperplasia suprarrenal congénita (HSC) es causada por mutaciones genéticas autosómicas recesivas, que codifican enzimas en la vía de la esteroidogénesis suprarrenal. Las mutaciones en la proteína reguladora aguda esteroidogénica (StAR) son las causantes de la hiperplasia lipoidea adrenal, la forma más grave de HSC, caracterizada por una ausencia de esteroidogénesis adrenal y gonadal, que se manifiesta por insuficiencia adrenal grave y ambigüedad genital ${ }^{1-3}$.

Las mutaciones en el gen StAR son frecuentes en la población japonesa, coreana y palestina, pero muy raras en el resto. Sin embargo, deben considerarse en el diagnóstico diferencial de cualquier recién nacido o niño pequeño con insuficiencia adrenal primaria, independientemente de donde sea originario ${ }^{1-3}$.

Su identificación oportuna permitirá establecer el manejo adecuado para mejorar su pronóstico y su calidad de vida futuras.

\section{REPORTE DE CASO}

Paciente de sexo femenino nacida en 2004 derivada a nuestro centro a los 23 días de vida por dismorfias faciales y alteraciones electrolíticas.

Entre los antecedentes destaca consanguinidad. Nacida por cesárea a consecuencia de bradicardia fetal, nace de término, peso $2,770 \mathrm{~g}$, talla $49 \mathrm{~cm}$. Al nacimiento requirió ventilación por presión positiva durante 30 segundos por dificultad respiratoria. Durante estancia hospitalaria presenta cuadro de sepsis e hiperbilirrubinemia a los trece días de vida, ameritando exanguinotransfusión. Presentó asimismo alteraciones electrolíticas, como hiponatremia e hiperpotasemia.

Desde el nacimiento se observaron algunas dismorfias, como hipertelorismo y pabellones auriculares de baja implantación.

En la exploración física se constató hiperpigmentación, hipotonía, fontanela anterior $3 \times 3$, sin ambigüedad genital, hipoplasia de labios menores, sin clitoromegalia y sin hirsutismo.
El estudio de electrolitos inicial mostró sodio de $134 \mathrm{mEq} / \mathrm{L}$ y potasio de $5.8 \mathrm{mEq} / \mathrm{L}$. El perfil tiroideo mostró hormona estimulante de la tiroides $3.3 \mu \mathrm{Ul} / \mathrm{mL}$ y tiroxina libre $1.4 \mathrm{ng} / \mathrm{dl}$, ambos valores dentro de rangos de referencia para la edad, así como ACTH > 1,250 pg/ml, 17-hidroxiprogesterona (17OHP) en zona gris; resto de perfil adrenal sin alteraciones (Tabla 1).

Con todos estos datos, se estableció un diagnóstico inicial de insuficiencia suprarrenal primaria, y se inició manejo con prednisona $18 \mathrm{mg} / \mathrm{m}^{2}$ subcutánea y fludrocortisona $0.05 \mathrm{mg}$ cada 12 horas.

La paciente presentaba fisuras palpebrales oblicuas, puente nasal deprimido, boca en carpa, cuello corto, pezones hiperpigmentados, labios mayores no hiperpigmentados, labios menores pequeños, clítoris normal e introito vaginal. Aunque la talla al nacer fue normal, posteriormente presentó talla baja, lo que, junto con el resto de hallazgos, planteaba la sospecha de síndrome de Turner. Por ello fue valorada por el servicio de genética a los 4 años de edad, que determinó un cariotipo 46,XY. Ante la duda de sexocromosomas, se repitió el cariotipo, con el mismo resultado, por lo cual se analizó la presencia de secuencias SRY, con resultado positivo.

Se realizó un genitograma que mostró uretra de características femeninas, sin observarse estructuras müllerianas.

El estudio de reserva testicular mostró ausencia de respuesta, con testosterona $<20 \mathrm{ng} / \mathrm{dl}$ en todos los tiempos durante esta.

Con todo ello, se sospechó un bloqueo alto en la vía adrenal.

Se solicitó análisis molecular del gen $S F 1$, sin encontrarse variantes patógenas.

Se solicitaron marcadores tumorales, con nivel de alfafetoproteína (AFP) de $6.9 \mathrm{ng} / \mathrm{ml}$, por encima del rango de referencia. Por presencia de SRY y AFP alterada, se decidió realizar gonadectomía, en la que se extrajo gónada semejante a testículo con epidídimo y conducto deferente en ambos lados; tamaño aproximado de $1 \times 1.5 \mathrm{~cm}$.

Se solicitó ultrasonido pélvico, que mostró imagen compatible con un útero disminuido de tamaño 
Tabla 1. Estudios de función adrenal y gonadal

\begin{tabular}{|c|c|c|c|c|c|c|c|c|}
\hline Fecha & $\begin{array}{c}\text { ACTH } \\
\mathrm{pg} / \mathrm{ml} \\
\mathrm{RR}(0.1-46)\end{array}$ & $\begin{array}{c}\text { Cortisol } \\
\mu \mathrm{g} / \mathrm{ml} \\
(\mathrm{RR} 5-25)\end{array}$ & $\begin{array}{c}17 \mathrm{OHP} \\
\mathrm{ng} / \mathrm{ml} \\
(\mathrm{RR}<2)\end{array}$ & $\begin{array}{c}\text { Andostenediona } \\
\mathrm{ng} / \mathrm{ml}\end{array}$ & $\begin{array}{l}\text { Renina } \\
\mathrm{pg} / \mathrm{ml}\end{array}$ & $\begin{array}{c}\text { DHEAS } \\
\mu \mathrm{g} / \mathrm{dl}\end{array}$ & $\begin{array}{c}\text { FSH } \\
\mathrm{mUI} / \mathrm{ml} \\
\text { (RR: } 0.5-7.37)\end{array}$ & $\begin{array}{c}\mathrm{LH} \\
\mathrm{mUI} / \mathrm{ml} \\
\mathrm{RR}(0.01-15.1)\end{array}$ \\
\hline 1. a valoración & $>1,250$ & 7.8 & 2.3 & 1.3 & & & & \\
\hline 1 año edad & $>1,250$ & & $<0.5$ & & $>500$ & $<15$ & & \\
\hline 12 años & 14.2 & & & & & & 161 & 17 \\
\hline
\end{tabular}

para edad de la paciente e identificación de un canal vaginal, pero sin imágenes compatibles con ovarios.

En la resonancia abdominopélvica realizada cuando la paciente tenía 10 años de edad no se observó útero, y las glándulas suprarrenales eran apenas perceptibles.

En 2018, se realizó estudio molecular del gen DAX1, que resultó con una secuenciación normal de los exones 1 y 2 del gen NROB1. Solo se apreció un genotipo hemicigoto para una variante muy común de tipo puntual-sinónima benigna.

A los 15 años de edad se decide iniciar tratamiento con estrógenos.

Se solicitó el estudio del gen StAR, que encontró una variante patogénica, que era la responsable del bloqueo alto de la vía adrenal.

En el seguimiento se observó que después de iniciados los estrógenos, la paciente recuperó la talla, superando incluso la talla blanco familiar, y presentaba un Tanner mamario 3.

\section{DISCUSIÓN}

La HSC engloba un grupo de enfermedades cuyo denominador común es un trastorno hereditario de la esteroidogénesis suprarrenal de cortisol. Es de herencia autosómica recesiva y se presenta en uno de cada 12,500 nacidos vivos. Es la causa más común de insuficiencia suprarrenal primaria en niños y adolescentes. Los objetivos del tratamiento son reemplazar la secreción fisiológica de glucocorticoides y mineralocorticoides para prevenir la pérdida de sal, controlar las manifestaciones asociadas con el hiperandrogenismo y mejorar los resultados en adultos $^{4-6}$.

La esteroidogénesis suprarrenal se produce mediante una serie de pasos facilitados por la expresión de enzimas específicas de la zona suprarrenal, y en los diferentes tipos de HSC este proceso se interrumpe en distintos puntos. La gravedad de la enfermedad y la presentación fenotípica varían según la ubicación y el alcance de las mutaciones o deleciones genéticas y el grado de afectación enzimática ${ }^{5}$.

En las formas graves o clásicas de HSC el déficit es completo y las manifestaciones se inician en la etapa fetal, mientras que en las formas moderadas o no clásicas el déficit es parcial y se manifiestan clínicamente en la infancia y adolescencia e incluso pueden pasar desapercibidas hasta la edad adulta ${ }^{7}$.

En una paciente mujer con virilización, vómitos, deshidratación y alteraciones electrolíticas, pensaríamos en una HSC. Si existen alteraciones electrolíticas, hay que determinar si se trata de un déficit de 21 hidroxilasa $(210 \mathrm{H})$ con una variedad perdedora de sal. Un nivel de $17 \mathrm{OHP}<200 \mathrm{ng} / \mathrm{dl}$ excluye el déficit de $210 \mathrm{O}$; si está en una zona intermedia (200-1,000 ng/dl), como en el caso de nuestra paciente, estaría indicado hacer un test de estimulación con hormona adrenocorticotropa (ACTH), cuyo resultado puede ayudar al diagnóstico.

El diagnóstico de hiperplasia lipoidea adrenal debe distinguirse de otras deficiencias combinadas de glucocorticoides y mineralocorticoides.

La distinción entre hiperplasia lipoidea adrenal y déficit de $21 \mathrm{OH}$ es simple; los pacientes con hiperplasia lipoidea adrenal tienen genitales externos femeninos, independientemente del cariotipo, y niveles muy bajos o indetectables de todas las hormonas 
esteroides, mientras que los pacientes con déficit de $210 \mathrm{H}$ tienen altas concentraciones de 21-desoxiesteroides, especialmente $170 \mathrm{PH}$, y los individuos afectados 46,XX están virilizados ${ }^{3}$.

Más difícil puede ser la distinción con otros déficits, como el de $3 \beta$-hidroxiesteroide deshidrogenasa cuando no se mide la 17OHP (que está muy elevada en la deficiencia de $3 \beta$-hidroxiesteroide deshidrogenasa) $)^{3}$.

Sin embargo, con base en el cuadro clínico de nuestra paciente (afectación de glándulas adrenales y gonadales, cariotipo 46,XY, forma perdedora de sal y sin virilización posnatal), el diagnóstico diferencial debe hacerse principalmente entre hiperplasia lipoidea adrenal (por mutación en el gen StAR) y deficiencia de la enzima de escisión de la cadena lateral del colesterol (por mutación en el gen CYP11A1).

La hiperplasia lipoidea adrenal es una forma grave y muy rara de HSC, debida a un defecto del gen $S t A R$, proteína esencial para el transporte del colesterol al interior de la mitocondria. En estos casos, existe un déficit grave de todos los esteroides suprarrenales y gonadales ${ }^{7}$.

La hiperplasia lipoidea adrenal se caracteriza por defectos graves en las glándulas suprarrenales y la conversión gonadal del colesterol en pregnenolona, el precursor de todos los esteroides ${ }^{1-3}$. La proteína StAR regula la transferencia de colesterol de la membrana mitocondrial externa a la interna, un paso clave en el inicio de la esteroidogénesis. La afectación de la actividad enzimática de esta proteína provoca la acumulación de colesterol en el citoplasma celular, que se vuelve tóxico y resulta en daño celular a las glándulas suprarrenales. Puesto que la expresión de la proteína StAR no es exclusiva a nivel adrenal, también puede haber daño de testículos y ovarios. Debido a que no puede existir ningún precursor en las vías mineralocorticoide, glucocorticoide ni hormonal sexual, el déficit es generalizado y la clínica se expresa con la depleción del metabolismo mineralocorticoide, glucocorticoide y hormonal sexual ${ }^{5,8}$.

La presentación clásica, como la de nuestra paciente, se caracteriza desde el periodo posnatal por ausencia completa de hormonas esteroideas, ACTH elevada, hipogonadismo hipergonadotrópico, ausencia de respuesta a esteroides, glándulas suprarrenales agrandadas con colesterol y ésteres de colesterol y pérdida salina. También se han descrito formas no clásicas asociadas a defectos genéticos que conllevan una actividad enzimática residual del 20-30\% y se manifiestan a partir de los 2-4 años de edad y en ocasiones incluso en la edad adulta, con un grado variable de insuficiencia suprarrenal y afectación variable de la función gonadal ${ }^{7}$.

Por su parte, la deficiencia de la enzima de escisión de la cadena lateral del colesterol participa en el primer paso de la vía esteroidogénica, codificada por CYP11A1, y es clínica y bioquímicamente idéntica a la hiperplasia lipoidea adrenal. Sin embargo, los pacientes suelen presentar atrofia suprarrenal y gonadal. También se han descrito formas no clásicas con inicio retardado de la insuficiencia suprarrenal y efecto gonadal variable, causadas por mutaciones que corresponden al 7-30\% de la actividad enzimática retenida ${ }^{5}$.

Un elemento que puede ayudar a diferenciar entre una HSC por una mutación en StAR o en CYP11A1 es que StAR no tiene efecto a nivel embrionario, por lo que los bebés suelen nacer a término, con peso y talla adecuados. El diagnóstico de hiperplasia lipoidea adrenal debería sospecharse en todos los neonatos fenotípicamente femeninos con evidencia de insuficiencia adrenal. El diagnóstico será confirmado documentando el valor bajo de hormonas esteroideas y sus metabolitos plasmáticos y urinarios, junto con la ausencia de respuesta al estímulo con gonadotropina coriónica humana o ACTH.

En las pruebas de imagen, inicialmente las glándulas suprarrenales aparecerán grandes por el acúmulo de lípidos, pero después se hacen atróficas, con menor contenido graso.

Otros diagnósticos diferenciales que hay que considerar son las mutaciones en el gen NROB1 (DAX1) o $S F-1$, que se expresan en la glándula suprarrenal y el eje reproductivo durante el desarrollo fetal y en la vida adulta, y cuyas variaciones están asociadas con HSC. La mutación en DAX1 causa una hiperplasia suprarrenal ligada a $X$, y se caracteriza por cariotipo $46, X Y$ con fenotipo femenino. Este gen actúa como represor transcripcional de genes implicados en la vía esteroidogénica. El DAX1 tiene influencia en el desarrollo gonadal, por lo que puede provocar 
alteraciones gonadales, que se manifiestan como hipogonadismo hipogonadotrópico, al contrario que en la HSC causada por mutación de StAR o CYP11A1, en las que el hipogonadismo es hipergonadotrópico 9 .

El factor esteroidogénico SF-1 (NR5A1) es otro factor de transcripción de receptores nucleares que juega un papel clave en el desarrollo adrenal y reproductivo humano. El SF-1 tiene un papel en la regulación suprarrenal y en la diferenciación gonadal y en el control hipotálamo-pituitario de la reproducción y el metabolismo ${ }^{10}$. Aunque es poco probable, hay que tenerlo en consideración a la hora del diagnóstico diferencial.

En conclusión, la HSC es una patología de origen genético asociada a mutaciones en genes que codifican para proteínas, cuya función es catalizar procesos metabólicos a nivel suprarrenal. Aunque las formas de presentación son variables, es importante la identificación oportuna de la causa subyacente para poder establecer cuanto antes un manejo adecuado que permita evitar secuelas, disminuir la morbimortalidad y mejorar la calidad de vida de los pacientes.

\section{FINANCIAMIENTO}

La presente investigación no ha recibido ninguna beca específica de agencias de los sectores públicos, comercial o con ánimo de lucro.

\section{CONFLICTO DE INTERESES}

Los autores declaran no tener conflicto de intereses.

\section{RESPONSABILIDADES ÉTICAS}

Protección de personas y animales. Los autores declaran que para esta investigación no se han realizado experimentos en seres humanos ni en animales.

Confidencialidad de los datos. Los autores declaran que han seguido los protocolos de su centro de trabajo sobre la publicación de datos de pacientes.

Derecho a la privacidad y consentimiento informado. Los autores han obtenido el consentimiento informado de los pacientes y/o sujetos referidos en el art'culo. Este documento obra en poder del autor de correspondencia.

\section{BIBLIOGRAFÍA}

1. Kaur J, Casas L, Bose HS. Lipoid congenital adrenal hyperplasia due to STAR mutations in a Caucasian patient. Endocrinol Diabetes Metab Case Rep. 2016;2016:150119.

2. Bizzarri C, Pisaneschi E, Mucciolo M, Pedicelli S, Galeazzi D, Novelli A, et al. Lipoid congenital adrenal hyperplasia by steroidogenic acute regulatory protein (STAR) gene mutation in an Italian infant: an uncommon cause of adrenal insufficiency. Ital J Pediatr. 2017;43:57.

3. Bose HS, Sato S, Aisenberg J, Shalev SA, Matsuo N, Miller WL. Mutations in the steroidogenic acute regulatory protein (StAR) in six patients with congenital lipoid adrenal hyperplasia. J Clin Endocrinol Metab. 2000;85(10):3636-9.

4. Prentice P. Guideline review: congenital adrenal hyperplasia clinical practice guideline 2018. Arch Dis Child Educ Pract Ed. 2021;106(6):354-7.

5. El-Maouche D, Arlt W, Merke DP. Congenital adrenal hyperplasia. Lancet. 2017;390:2194-210.

6. Rodríguez A, Ezquieta B, Labarta Jl, Clemente M, Espino R, Rodriguez A, et al. Recommendations for the diagnosis and treatment of classic forms of 21-hydroxylase-deficient congenital adrenal hyperplasia. Ann Pediatr. 2017;87(2):116.e1-116.e10.

7. Labarta Aizpún Jl, de Arriba Muñoz A, Ferrer Lozano M. Hiperplasia suprarrenal congénita. Protoc Diagn Ter Pediatr. 2019;1:141-56.

8. Herrera-Gómez A. Hiperplasia suprarrenal congénita: origen de trastornos del desarrollo y diferenciación sexual. Medicas UIS. 2015;28(1):125-32.

9. Phelan JK, McCabe ER. Mutations in NR0B1 (DAX1) and NR5A1 (SF1) responsible for adrenal hypoplasia congenita. Hum Mutat. 2001;18(6): 472-87.

10. Suntharalingham JP, Buonocore F, Achermann JC. DAX-1 (NROB1) and steroidogenic factor-1 (SF-1, NR5A1) in human disease. Best Pract Res Clin Endocrinol Metab. 2015;29(4):607-19. 